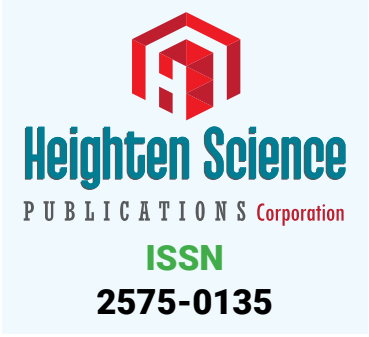

2575-0135

\title{
Use of essential oils as new food preservatives (Case: Eucalyptus grandis and Eucalyptus crebra)
}

\author{
Sendanyoye Marcel* \\ University of Rwanda, Kigali, Rwanda
}

*Address for Correspondence: Sendanyoye

Marcel, University of Rwanda, Kigali, Rwanda, Tel: +250783493980; Email:

ssmarcellomarcello@yahoo.com

Submitted: 22 October 2018

Approved: 01 November 2018

Published: 02 November 2018

Copyright: (c) 2018 Marcel S. This is an open access article distributed under the Creative Commons Attribution License, which permits unrestricted use, distribution, and reproduction in any medium, provided the original work is properly cited

Keywords: Eucalyptus grandis; Eucalyptus crebra Leave's essential oils; Acanthoscelides obtectus and Stophilus oryzae; Rhizopus nigricans; Food preservatives

Check for updates

\section{Abstract}

This study purposed to study the Preservative agents that are required to ensure that manufactured foods remain safe and unspoiled; work was conducted to evaluate the efficacy of essential oils from two eucalyptus species, Eucalyptus grandis and Eucalyptus crebra in food preservatives; to run this experiment flesh eucalyptus leaves collected from Ruhande Arboretum forest were submitted to hydrodistillation and yields(amount) of 0.38 and $0.34 \%$ for Eucalyptus grandis and Eucalyptus crebra were obtained, respectively. Phaseolus vulgaris, Sorghum condatum, cooked Ipomoea batatas (sweet potatoes) and bread were the sample foods used to assess their preservative efficacy. Acanthoscelides obtectus and Stophilus oryzae were used as pests for Phaseolus vulgaris and Sorghum condatum respectively. For bread and cooked Ipomoea batatas, Rhizopus nigricans are used to assess the efficacy of these two essential oils to inhibit their growth; the obtained results revealed that those essential oils could act as insecticide in the storage of Phaseolus vulgaris and Sorghum condatum. Essential oil from Eucalyptus grandis protected these two foods against pests in the periods of 4 and 9 days, respectively while essential oil from Eucalyptus crebra protected them for the periods of 6 and 11days, respectively.

\section{Introduction}

People are uncomfortable with the thought of having their food chemically treated to boost its shelf life. The environmental problems caused by overuse of inorganic and chlorinated organic compounds have been the matter of concern for both scientists and public in recent years. Our objective in the present context is to review the roles of Eucalyptus grandis and Eucalyptus crebra as food preservatives and its use as a natural pesticide, which could be another supporting ecosystem service and pest and disease management (Abad et al. 2007). The genus Eucalyptus contains concerning 700 species; among them, over three hundred contain volatile oils in their leaves. Essential oils of assorted eucalyptus species square measure employed in the pharmaceutical, toiletries, cosmetics, and food industries [1]. These broad applications square measure thanks to the antiseptic, antihyperglycemic, the anti-inflammatory drug, flavouring, and inhibitory properties of the molecules gift within the oil [2]. The antimicrobial activity of eucalyptus oils has been found to vary considerably among microbic species and among microbic strains. The sturdy antimicrobial activity could also be directly related to their major compounds within the oil (such as one,8-cineole and $\alpha$-pinene) or with the natural action between the main and minor constituents [3]. Previous results reported that Gram positive bacterium square measure a lot of vulnerable than Gram negative bacteria; what is more, activity against fungi and yeasts (Candida albicans and genus Saccharomyces cerevisiae) has conjointly been detected [4], in keeping with one in all the reports, Eucalyptus odorata had the strongest activity against bacterium and yeasts whereas E. bicostata had the most effective antiviral activity (Salem et al; 2012) [3]. Though many studies concerning eucalyptus oils are revealed [5], solely few of them 
evaluated their activity against morbific and food spoilage microorganisms [4]. Despite the well-reported antimicrobial activity in vitro, the food trade has applied eucalyptus essential oils principally as flavoring agents. Therefore, the utilization of essential oils as preservatives in food has been restricted. as a result of the desired concentration against microorganisms is laid low with the interactions of the oil compounds with the food matrix parts, higher concentrations square measure required to realize ample activity. This negatively impacts the organoleptic properties of the ultimate product [6]. Due to their odors and interesting biological activities, these oils are used in food industries as food additives, in cosmetic, soaps and perfums industries (Koul et al. 2008). More recently, they have been used for aromatherapy and as herbal medicines. For this reason, application of some essential oils for food preservation can negatively influence its taste or odor and therefore should be combined with each other or with other antimicrobials to avoid this unwanted side effect [7].

Due to these reported biological activities from essential oils, this study intended to verify possible use of essential oils from two species of eucalyptus, Eucalyptus crebra and Eucalyptus grandis for the inhibition of fungi growth, elimination of fungi and the insecticidal activity. Its aim is to assess if these essential oils can be used as a new natural food preservative. For assessing these biological activities from essential oils, food mould, Rhisopus nigricans isolated from spoiled cooked Ipomoea batatas (sweet potatoes) and bread, on one side, and two bruchids, Acanthoscelides obtectus and Sitophilus oryzae insects isolated from infested Phaseolus vulgaris (beans) and Sorghum condatum (sorghum), respectively, were used [8,9].

\section{Nature and composition of eucalyptus essential oils}

The eucalyptus oil is a complex mixture of a variety of monoterpenes and sesquiterpenes, and aromatic phenols, oxides,ethers, alcohols, esters, aldehydes and ketones; however, the exact composition and proportion of which varies with species [10]. The pesticidal activity of eucalyptus oils has been due to the components such as 1,8-cineole, citronellal, citronellol, citronellyl acetate, p-cymene, eucamalol, limonene, linalool, $\alpha$-pinene, $\Upsilon$-terpinene, $\alpha$-terpineol, alloocimene, and aromadendrene (Li et al., 1995, 1996; Duke, 2004; Batish et al., 2006; Su et al. 2006) [11-13]. The major components identified in essential oil with pesticidal activity extracted from various Eucalyptus species; however, the bioactivity of the essential oil depends upon the type and nature of the constituents and their individual concentration. It further varies with species, season, location, climate, soil type, age of the leaves, fertility regime, the method used for drying the plant material, and the method of oil extraction [10].

The various components of eucalyptus essential oil act synergistically (and not additively) to bring the overall pesticidal activity [12]. Among the various components of eucalyptus oil, 1,8-cineole is the most important one and, in fact, a characteristic compound of the genus Eucalyptus, and is largely responsible for a variety of its pesticidal properties (Duke, 2004).

\section{Methodologies}

\section{Collection of eucalyptus leaves}

In the morning of March 2015, Fresh eucalyptus leaves from mature Eucalyptus grandis and Eucalyptus crebra were sampled from Arboretum forest of Ruhande in the parcels number 220 and 24, respectively. The sampled eucalyptus leaves were weighed by electronic balance (US-TT1000) and the mass obtained are recorded as $2789.4 \mathrm{~g}$ and $2676.47 \mathrm{~g}$ for Eucalyptus grandis and Eucalyptus crebra, respectively.

\section{Preparation of plant materials and extraction}

Weighted fresh eucalyptus leaves were then cut into small pieces and they were submitted to hydrodistillation method which is a common method used in the extraction 
of essential oil. During this method, water vaporizes and produces steam, which carries the most volatile of the aromatic material with it. The steam is then chilled in a condenser and the resulting distillate that includes essential oil and water is collected. Then the dean-stack apparatus is used to separate essential oil from water. The oil samples obtained from hydrodistillation were freed from water by adding anhydrous sodium sulfate ( $\mathrm{Na} 2 \mathrm{SO} 4)$ and absolute oil samples obtained were conserved in small opaque vials. The amount of extracted oil was determined, the quantity obtained are $10.6 \mathrm{~g}$ of Eucalyptus grandis and 9.1g of Eucalyptus crebra. From these quantities the percentage yield of eucalyptus essential oil have been calculated as follow;

$$
\text { Yield }(\%)=\frac{\text { weight of essential oil }}{\text { weight of leaves }} \quad \mathrm{X} 100
$$

\section{Biological activity assessment}

Antifungal activity assessment: To assess the fungicidal activity, mycelium of Rhizopus nigricans was previously grown on either bread or on cooked Ipomoea batatas (sweet potatoes). A small portion of mycelia was revivified on the bread or cooked Ipomoea batatas previously spread with essential oils. Thereafter, beakers containing these foods were kept at 250C and 75\% of relative humidity. This experiment was done in triplicate and control experiment without any essential oil was also conducted in the same time (Musyimi and Ogur, 2008).

Cooked food preservation assessment: To assess this activity, both healthy bread and cooked Ipomoea batatas (sweet potatoes) were used. A quantity of a given essential oil was smeared on the total surface of small portion of one of these foods. The food was then kept in a sterilized beaker at the optimum temperature of Rhizopus nigricans, 250C [14], (Gravesen et al., 1994) at 75\% of relative humidity. The observation was done during one month. The experiment test was conducted in parallel with control experiment without essential oil and the experiment was repeated three times.

Insecticidal activity assessment: Both Acanthoscelides obtectus and Sitophilus oryzae were isolated from infected Phaseolus vulgaris (beans) and Sorghum condatum, respectively. To assess the anti Acanthoscelides obtectus activity, forty grains of Phaseolus vulgaris were put in small envelop (paper bag) with $1 \mathrm{~kg}$ of capacity as containers. Then, five drops are used to allow oil to reach all beans, essential oil were added to beans to show us how oil protects insecticidal activities. To allow essential oil to reach all beans the container was manually agitated during one minute. Thereafter, 40 insects of Acanthoscelides obtectus, were added in the envelope containing treated grains and the whole container was kept in the oven at $30^{\circ} \mathrm{C}$ [15]. The observation was done daily during 45 days to increase the chance of 40 insects to attack beans and by counting insects that are not affected by essential oils. The experiment was done in triplicate. Control experiment without essential oil was conducted in parallel.

The anti Sitophilus oryzae activity was assessed using the same methodology as what used for Acanthoscelides obtectus. The only difference is that thirty-five grams of Sorghum condatum grains were infested with 25 insects of Sitophilus oryzae.

\section{Results and Discussion}

\section{Amount of essential oil from the leaves of Eucalyptus grandis and Eucalyptus crebra}

From $2789.4 \mathrm{~g}$ of the leaves of Eucalyptus grandis $11 \mathrm{~mL}$ (10.6 grams) of essential oil was obtained while from $2676.47 \mathrm{~g}$ of fresh leaves of Eucalyptus crebra, $10 \mathrm{~mL}$ (9.1 grams) of essential oil was obtained. These mean, yields in essential oils of $0.38 \%$ and $0.34 \%$ for Eucalyptus grandis and Eucalyptus crebra, respectively. Variation in the yield of essential oils was previously presented (Najum et al., 2005). According to the 
author, yield in essential oil of Eucalyptus crebra ranged from $0.291 .33 \%$ while that of Eucalyptus grandis ranged from $0.30-1.78 \%$. The obtained yields in this work remain in real range but do not match the range for each species. This is due to fact that the concentration and amount of essential oils depends on the external environmental condition including soil composition, under favorable weather conditions, the method of extraction and the refining process [16]. In addition, the age of plant significantly impacts on the quantity of essential oil since it increases rapidly as the plant approaches vegetative maturity (Weller, 2010).

\section{Biological activity of essential oils}

Essential oils are known to exhibit antimicrobial properties that are lethal or static to the growth of bacteria, fungi, or virus [17]. With respect to their preservative and antimicrobial properties, essential oils are used in the prevention of insects and treatment of infections in food products, in cosmetics and as disinfectants [17]. With pure essential oils and herbal medicines in their complete state you can heal and nourish without the traditional side effects of drugs (Najum, 2005). Oil of eucalyptus was first registered in 1948 as insecticide and miticide (EPA, 1993). Thus the potential insecticidal and antifungal activity of eucalyptus essential oils has been found to vary significantly within different insect and fungi species and these potentials activity may be directly associated with their major compounds in the oil (1, 8-cineole and $\alpha$-pinene) or with the synergy between the major and minor constituents [18]. In this study both antifungal and insecticidal activity were assessed.

Fungicidal activity of essential oils: Eucalyptus essential oils and their major constituents possess toxicity against a wide range of microbes including bacteria and fungi, both soil-borne and post-harvest pathogens. They have been found to reduce mycelial growth [19], and inhibit spore production and germination (Oluma and Garba, 2004). Ramezani et al. [20] showed that volatile oil from lemon-scented eucalyptus and its major constituent monoterpene citronellal possessed a wide spectrum of fungicidal activity and inhibited the radial growth and dry weight of six phytopathogenic fungi. Recently, Lee et al. (2007) demonstrated that lemon-scented eucalyptus oil controlled the apple gray mold by Cermelli etal. (2008) the study concluded that eucalyptus oil could be used for the control of respiratory tract bacteria. Su et al. (2006) demonstrated the antifungal activity of essential oils from Eucalyptus grandis, are against the mildew and wood rot fungi viz. Based on the study, the authors opined that essential oil from Eucalyptus grandis be an excellent choice as a wood preservative and preservation of leather goods and wood artifacts. Cimanga et al. [12], demonstrated the antibacterial activity of essential oil extracted from Eucalyptus are against Pseudomonas aeruginosa. They concluded that composite essential oils were more effective than the additive activity of their major constituents such as 1,8-cineole, $\alpha$-pinene, and p-cymene. Recently, Tzortzakis [21], demonstrated that essential oil vapours from E. grandis offer a good choice for maintaining postharvest freshness and firmness of strawberry and tomato during storage and transit. Further, no change was observed in sweetness, and organic acid and total phenolic content upon exposure to oil vapours [21].

Further, studies have also documented that eucalyptus essential oils are effective even against resistant strains of microbes. For example, Sherry et al. [22], demonstrated that a topical application of eucalyptus oil can effectively remove the methicillin resistant Staphylococcus aureus infection and were inhibited by the commercially available eucalyptus oil containing 63\% 1,8-cineole. Eucalyptus oils not only show toxicity against a wide range of fungi and bacteria but also possess antiviral activity.

The assessment of antifungal activity was done by putting a very small portion of Rhizopus nigricans mycelia on the central of small pieces of cooked Ipomoea batatas (sweet potatoes) or bread moistened with essential oil. Essential oils from both Eucalyptus crebra and E. grandis significantly delayed the growth of fungi on either Ipomoea batatas or bread this in comparison with control experiment On Ipomoea batatas essential oils 
from E. crebra and Eucalyptus grandis delayed the growth of mycelia for 7 and 8 days of active mycelial growth, respectively while on bread, these two essential oils completely inhibited the growth of mycelia during one month of observation (Table 1).

Results from this study is supported by findings of Knigh and Allah (2009) who reported that eucalyptus essential oil delayed mycelium elongation and reduce sporulation for each fungus species in culture. The difference between antifungal activities from both species of eucalyptus may due to their different chemical composition. Bread was more resistant to the mycelia compared to Ipomoea batatas. This may be due to the higher humidity found in cooked Ipomoea batatas than that found in bread. Furthermore, the use of salt during bread manufacture constitutes another advantage for its conservation against mould, since Dalmasso (1985) frequently reported the antifungal activity of salt. In first days, essential oils significantly inhibited the growth of mycelia on Ipomoea batatas. However, after some days, they lost this antifungal activity and mould started to grow. This speedy loss of activity may be due to faster volatilization of bioactive compounds found in essential oils [23].

Preservation of cooked foods using essential oils: In experiment of preservation, it has been observed that the essential oil from E. grandis and E. crebra show an antifungal activity. Try in food preservative show us that after four and three weeks, no mycelium has been developed on bread and cooked Ipomoea batatas moistened with essentials oils from E. grandis and E. crebra respectively. After these weeks no food mould started to develop on bread and cooked Ipomoea batatas with essential oils while on small pieces of cooked Ipomoea batatas and bread without essential oil the mould start to develop after three and eight days respectively. This observation showed the powerful use essential oils from two eucalyptus species (E. grandis and E. crebra) as food preservatives

Insecticidal activity of essential oils: In the present work, it was verified that the essential oils from E. grandis and E. crebra could be a good alternative as grains preservatives against Acanthoscelide. obtectus and Sitophilus oryzae. In the control experiment, bean grains (Phaseolus vulgaris) without essential oils were infested, and insects' larval continue their development causing visible damages at the beans. Acanthoscelide obtectus insects seriously perforated different beans, which were previously healthy. After infestation of Acanthoscelides obtectus insects the female insects lay eggs on beans and after fecundity, the eggs give larval during 30-45 days. Thus, the larval penetrate into the beans, eating the content by making many holes on Phaseolis vulgaris grain.

Essential oils from the leaves of E. grandis and E. crebra significantly affected the kinetic mortality of both Acanthoscelide obtectus and Sitophilus oryzae. After three days of incubation, packets containing essential oils of E. grandis and E. crebra, knew the death of 36 and 29 insects over 40 insects used, respectively, while only one insect dead in the control experiment. After 5 days, all insects in contact with essential oil from E. grandis leaves dead against only 5 insects in the control experiment. Furthermore, after 7 days of incubation, those in contact with essential oil from E. crebra dead and this in comparison with 15 insects in the control experiment. This big difference in mortality rate indicated that both essential oils studied affected the life of Acanthoscelide obtectus insects. The

Table 1: Fungicidal activity of essential oil from Eucalyptus crebra and Eucalyptus grandis against Rhizopus nigricans.

\begin{tabular}{|c|c|c|c|c|c|c|}
\hline \multirow{2}{*}{ Day } & \multicolumn{2}{|c|}{ Control experiment } & \multicolumn{2}{c|}{ E. crebra } & \multicolumn{2}{c|}{ E. grandis } \\
\cline { 2 - 8 } & I. batatas & Bread & I. batatas & Bread & I. batatas & Bread \\
\hline 1 & - & - & - & - & - & - \\
\hline 2 & + & - & - & - & - & - \\
\hline 3 & ++ & - & - & - & - & - \\
\hline 4 & +++ & - & - & - & - & - \\
\hline 5 & +++ & - & - & - & - & - \\
\hline 6 & +++ & + & - & - & - & - \\
\hline 7 & +++ & ++ & + & - & - & - \\
\hline 8 & +++ & +++ & ++ & - & + & - \\
\hline
\end{tabular}


figure 1 indicates the daily kinetic mortality of Acanthoscelide obtectus on Phaseolus vulgaris grains moistened with essential oils from either E. crebra or E. grandis.

Considering insecticidal activities from both E. grandis and E.crebra, we remarked that essential oil from E. grandis exhibited a higher activity on Acanthoscelides obtectus insects compared to one from E. crebra. This high activity remarked may be due to the presence of oxygenated monoterpenoid in essential oil from E. grandis contain as reported by Regnault-Roger [24] and Lamiri (2001).

The same results were obtained when Sorghum condatum grains were used. Essential oils seriously affected life of Stophilus oryzae insects (Figure 2).

Figure 2: Plot of daily mortality of Sitophilus oryzae. After four days of incubation, packets containing essential oils of E. grandis and E. crebra, knew the death of 10 and 8 insects, over 25 insects used, respectively, while only one insect dead in the control experiment. On 10th day of incubation, all insects in contact with essential oil from E. grandis leaves dead against only 13 insects in the control experiment. Furthermore, on 12th day of incubation, all those in contact with essential oil from E. crebra dead and this in comparison with 16 insects in the control experiment. Results from this study showed that Stophilus oryzae insects were more resistant to both essential oils than Acanthoscelides obtectus insects. The reason of this should be further investigated. In general, this potential insecticidal activity of essential oil could be explained by examining their chemical composition. As Regnault-Roger [24] and Lamiri (2001) have reported it, the essential oil, which contains oxygenated monoterpenoid, has stronger insecticidal activity compared to those containing hydrocarbons. Therefore, the insecticidal potential activity is proportional to their total oxygenated monoterpenoid content, and hence inversely proportional to the amount of hydrocarbons. From this statement we can say that the essential oil from E. grandis contain a larger proportion of highly oxygenated monoterpenoid compared to those from E. crebra. According to Rice et al. (1994) and Regnault-Roger et al. [25], terpinen-4-ol, 1, 8- cineol, verbenone and camphor showed pronounced anti Acanthoscelides obtectus adults activity. Ketones were generally more active than alcohols and both were more active than hydrocarbons. Similar trends regarding the fumigant activity of several monoterpenoid against a number of insect species have already been reported by Regnault-Roger [24] and Hamraoui (1995).

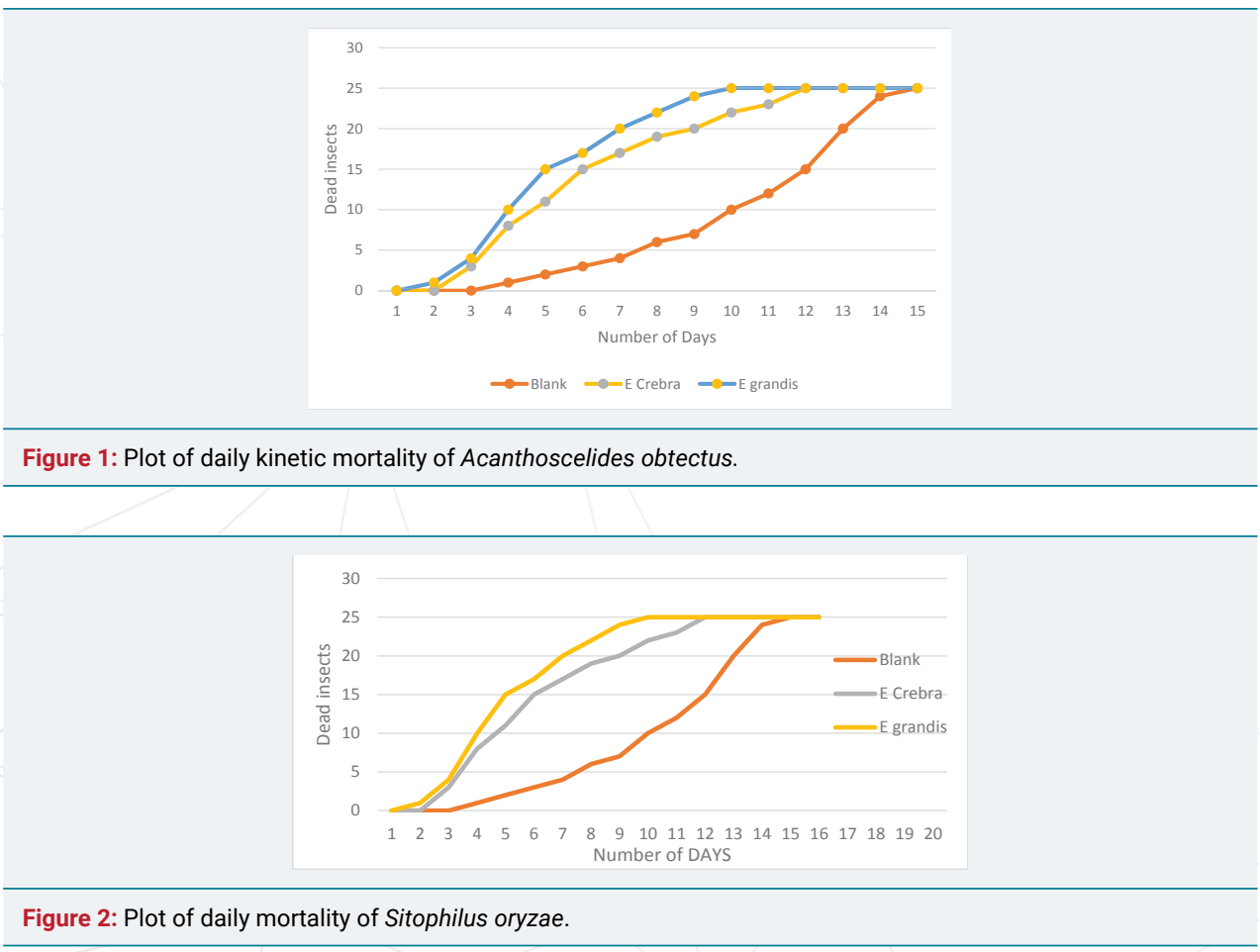




\section{Conclusion}

From this study, two eucalyptus essential oils were successively extracted from E.crebra and E. grandis leaves for discovering new food preservatives. The biological activities of essential oils evaluated in this work show that they could be used in food preservation. Longtime, the Rwandan farmers use certain plants in the protection of foodstuff; for this, as scientist we have to think the evaluation on the efficacy of essential oils from different eucalyptus leaves in food preservation. Thus, the insecticidal and fungicidal potential of extracted essential oils on foods mould and insects (Acanthoscelides obtectus and Sitophilus oryzae) reveal that they were promising and should be well studied to be applied in food preservation.

\section{References}

1. Ben Marzoug HN1, Romdhane M, Lebrihi A, Mathieu F, Couderc F, et al. Eucalyptus oleosa essential oils: chemical composition and antimicrobial and antioxidant activities of the oils from different plant parts (stems, leaves, flowers and fruits). Molecules. 2011;16: 1695-1709. Ref.: https://goo.gl/2cjY3a

2. Takahashi T, Kokubo R, Sakaino M. Antimicrobial activities of eucalyptus leaf extracts and flavonoids from Eucalyptus maculata. Lett Appl Microbiol. 2004; 39: 60-64. Ref.: https://goo.gl/mCnjWB

3. Elaissi A1, Rouis Z, Salem NA, Mabrouk S, ben Salem $Y$, et al. Chemical composition of 8 eucalyptus species' essential oils and the evaluation of their antibacterial, antifungal and antiviral activities. BMC Complement Altern Med. 2012; 81: 1-15. Ref.: https://goo.gl/TnMm5j

4. Tyagi AK, Malik A. Antimicrobial potential and chemical composition of Eucalyptus globulus oil in liquid and vapour phase against food spoilage microorganisms. Food Chemistry. 2011; 126: 228235. Ref.: https://goo.gl/BMoLXn

5. Pereira V, Dias C, Vasconcelos MC, Rosa E, Saavedra MJ. Antibacterial activity and synergistic effects between Eucalyptus globulus leaf residues (essential oils and extracts) and antibiotics against several isolates of respiratory tract infections (Pseudomonas aeruginosa). Industrial Crops and Products. 2014; 52: 1-7. Ref.: https://goo.gl/ZcbNT1

6. Hyldgaard M, Mygind T, Meyer RL. Essential oils in food preservation: mode of action, synergies, and interactions with food matrix components. Front Microbiol. 2012; 3: 12. Ref.: https://goo.gl/UVEnoK

7. Rentsenkhand T. Effect of essential oils and their combinations on food-spoilage. Szeged: University of Szeged. 2010; 79. Ref.: https://goo.gl/JS5skB

8. Shapaval V, Schmit J. Meretro T. A characterization of food spoilage fungi by FTR spectroscopy. Journal of applied microbiology. 2012; 114: 788-796. Ref.: https://goo.gl/YnPHsG

9. Thakur D. Invasion and threats of Acanthoscelides obtectus (Say) (Coleloptera: Bruchidae) to kidney. Paper of 10th International Working Conference on Stored Product Protection. 2012; Ref.: https://goo.gl/E5Q7tP

10. Brooker $\mathrm{MIH}$, Kleinig DA. Field Guide to Eucalyptus. Vol.1. South-eastern Australia, Third edition. Bloomings, Melbourne. 2006; Ref.: https://goo.gl/9VePPJ

11. Watanabe K, Shono Y, Kakimizu A, Okada A, Matsuo N, et al. New mosquito repellent from Eucalyptus camaldulensis. J Agric Food Chem. 1993; 41: 2164-2166. Ref.: https://goo.gl/4rnxu3

12. Cimanga K1, Kambu K, Tona L, Apers S, De Bruyne T, et al. Correlation between chemical composition and antibacterial activity of essential oils of some aromatic medicinal plants growing in the Democratic Republic of Congo. J Ethnopharm. 2002; 79: 213-220. Ref.: https://goo.gl/d6fvHr

13. Liu X, Chen Q, Wang Z, Xie L, Xu Z. Allelopathic effects of essential oil from Eucalyptus grandis E. urophylla on pathogenic fungi and pest insects. Front. Forestry China. 2008; 3: 232-236. Ref.:Ref.: https://goo.gl/Tgys3L

14. Znidarsic $P$, Komel R, Pauko A. Influence of some environment factors of Rhizopus nigricans. World journel of microbiology and biotechnology. 2002; 16: 589-593. Ref.: https://goo.gl/Gwb8LH

15. Najum RM, Hanif MA, Rashid U. Chemical composition and intra provenance variation for content of essential oil in eucalyptus crebra. Asian journal of plant sciences. 2005; 4: 519-523. Ref.: https://goo.gl/BpcFZM

16. Abdelmajeed $D$. The effect of environmental stress on quantitative essential oil of aromatic and medicinal plants. Archives des sciences. 2013; Ref.: https://goo.gl/x3Ybrk 
17. Sewanu S. The chemical composition, antimicrobial and antioxidant properties of the essential oils of Tulbaghia violacea Harv. and Eucalyptus grandis. Thesis. 2012; $19-24$.

18. Isman MB. Plant essential oils for pest and disease management. Crop protection. 2000; 19: 603608. Ref.: https://goo.gl/NoLk78

19. Fiori ACG, Schwan-Estrada KRF, Stangarlin JR, Vida JB, Scapim CA, et al. Antifungal activity of leaf extracts and essential oils of some medicinal plants against Didymella bryoniae. J Phytopathol. 2000; 148: 483-487. Ref.: https://goo.gl/Pvu71o

20. Ramezani H, Singh HP, Batish DR, Kohli RK. Antifungal activity of the volatile oil of Eucalyptus citriodora. Fitoterapia. 2002; 73: 261-262. Ref.: https://goo.gl/K7XDfo

21. Tzortzakis NG. Maintaining postharvest quality of fresh produce with volatile compounds. Innovative Food Sci. Emerging Technol. 2007; 8: 111-116. Ref.: https://goo.gl/BrL9Ru

22. Sherry E, Boeck H, Warnke PH. Topical application of a new formulation of eucalyptus oi phytochemical clears methicillin-resistant Staphylococcus aureus infection. Am J Infect Control. 2001; 29: 346. Ref.: https://goo.gl/M7f8rR

23. Rao V. Extraction of essential oil and its application. Project Report. 2007; 9-35. Ref.: https://goo.gl/bhxZJd

24. Regnault-Roger C1, Hamraoui A, Holeman M, Theron E, Pinel R. Insecticidal effect of essential oils from Mediterranean plants upon Acanthoscelides obtectus (Coleoptera, Bruchidae) a pest of kidney bean (Phaseolus vulgaris L). J Chem Ecol. 1993; 19: 1233-1244. Ref.: https://goo.gl/3G9HXL

25. Regnault-Roger C, Hamraoui A. Fumigant toxic activity and reproductive inhibition induced by monoterpenes on Acanthoscelides obtectus (Say) (Coleoptera), a Bruchid of kidney bean (Phaseolus vulgaris L). African Entomology. 1995; 31: 291-299. Ref.: https://goo.gl/x8teoo

26. Somda I, Leth V, Sérémé P. Antifungal effect of Cymbopogon citratus, Eucalyptus camaldulensis and Azadirachta indica oil extracts on sorghum feed-borne fungi. Asian Journal of Plant Sciences. 2007; 6:1182-1189. Ref.: https://goo.gl/tQ1CXH

27. Sartorelli $P$, Marquioreto AD, Amaral-Baroli A, Lima MEL, Moreno PRH. Chemical composition and antimicrobial activity of the essential oils from two species of Eucalyptus. Phytotherapy Research. 2007; 21: 231-233. Ref.: https://goo.gl/zSSVrR

28. Abdel Halim AS, Morsy TA. The insecticidal activity of Eucalyptus globulus oil on the development of Musca domestica third stage larvae. J Egypt Soc Parasitol 2005; 35: 631-636. Ref.: https://goo.gl/Jfgoev

29. Romano CM, Móras A, de Oliveira M, Pereira JM, Gularte MA, et al. Control of Acanthoscelides obtectus in black beans with diatomaceus earth. Alternative Methods to Chemical Control. 2005; 877-882. Ref.: https://goo.gl/d2f5nr

30. O’Reilly-Wapstra JM, McArthur C, Potts BM. Linking plant genotype, plant defensive chemistry and mammal browsing in a Eucalyptus species. Funct Ecol. 2004; 18: 677-684. Ref.: https://goo.gl/e2KA3k

31. Regnault-Roger C, Hamraoui A. The effect of environmental stress on quantitative essential oil of aromatic and medicinal plants. Archives des sciences. 20136; 5: 2058.

32. Trivedi NA, Hotchandani SC. A study of the antimicrobial activity of oil of Eucalyptus. Indian $J$ Pharmacol. 2004; 36: 93-95. Ref.: https://goo.gl/Nj5y2b

33. Willis D. Botanical essential oils as natural food preservatives. Science against microbial pathogens. 2013; 1354-11354 